\title{
Seasonal Weather-Related Decision Making for Cattle Production in the Northern Great Plains
}

\author{
By Justin L. Reeves, Justin D. Derner, Matt A. Sanderson, Scott L. Kronberg, \\ John R. Hendrickson, Lance T. Vermeire, Mark K. Petersen, and J. Gonzalo Irisarri
}

\section{On the Ground}

- Ranching is a challenging and sometimes risky business, with cattle production (and associated enterprise income) largely being dependent on seasonal weather patterns and corresponding forage production. To help reduce this risk, the USDA-Agricultural Research Service performed a multistate study of seasonal weather effects on cattle production across the Northern Great Plains (Wyoming, North Dakota, and Montana).

- Cool, wet springs and longer, cooler growing seasons increased cattle production across the Northern Great Plains. Knowledge of these seasonal weather influences on cattle production is important for management decision making, but practical application of this knowledge remains problematic.

- Increased enterprise flexibility to deal with variable forage production can be achieved by using seasonal weather forecasts, as well as reducing base cow-calf herd numbers to less than $100 \%$ of typical ranch carrying capacity. Yearlings or seasonal contract grazing can then be used to increase grazing to use additional forage in good years.

- Recently launched USDA Regional Climate Hubs will deliver science-based knowledge, practical information, management and conservation strategies, and decision tools to ranchers that will help them adapt to weather variability and changing climatic conditions.

Keywords: ranching, adaptive management, climate change, reducing risk, Climate Hubs.

Rangelands 37(3):119-124

doi: $10.1016 /$ j.rala.2015.03.003

(C) 2015 The Society for Range Management

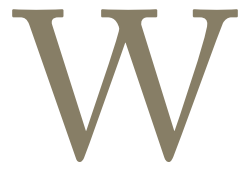

hat will forage production be like this year and how should I adjust my stocking rates? These are two of the most crucial questions that ranchers face each year. However, dependable answers are very difficult to come by, particularly in advance of the grazing season. Cattle production is a challenging business, as seasonal weather patterns, especially drought (Fig. 1), can highly influence bottom lines for ranchers. In the Northern Great Plains, extreme fluctuations in forage production on rangelands can occur from year-toyear due to weather variability. For example, forage production dropped 20-fold between 2001 (a wet year; 1,976 pounds per acre), and 2002 (a dry year; 100 pounds per acre) in Cheyenne, Wyoming. ${ }^{1}$ Ranchers respond to such weather and forage production variability across years by using a range of management strategies, including hay production or purchase, not grazing pastures to reserve forage in case of drought ("grassbanking"), diversifying operations with other revenue streams (e.g., wildlife, hunting, ecotourism), and trying to match forage demand to forage availability. ${ }^{2,3}$ As a part of matching forage demand and availability, however, one underutilized strategy is incorporation of weather forecasts into yearly decision making. ${ }^{3,4}$

Long-term research data can provide a clearer understanding of how seasonal weather patterns influence cattle production. Fortunately for ranchers in the Northern Great Plains, the USDA-Agricultural Research Service (ARS) has multiple long-term cattle weight gain datasets across the Northern Great Plains dating as far back as the 1930s (Box 1). Researchers with ARS have used these historical datasets in a multistate, collaborative effort to learn how seasonal weather influences cattle production from rangelands in this region. Here, we showcase the lessons learned and how ranchers can use this information to assist with decision making for their operations to reduce risk associated with seasonal weather variability. In particular, reduced risk can be accomplished by 


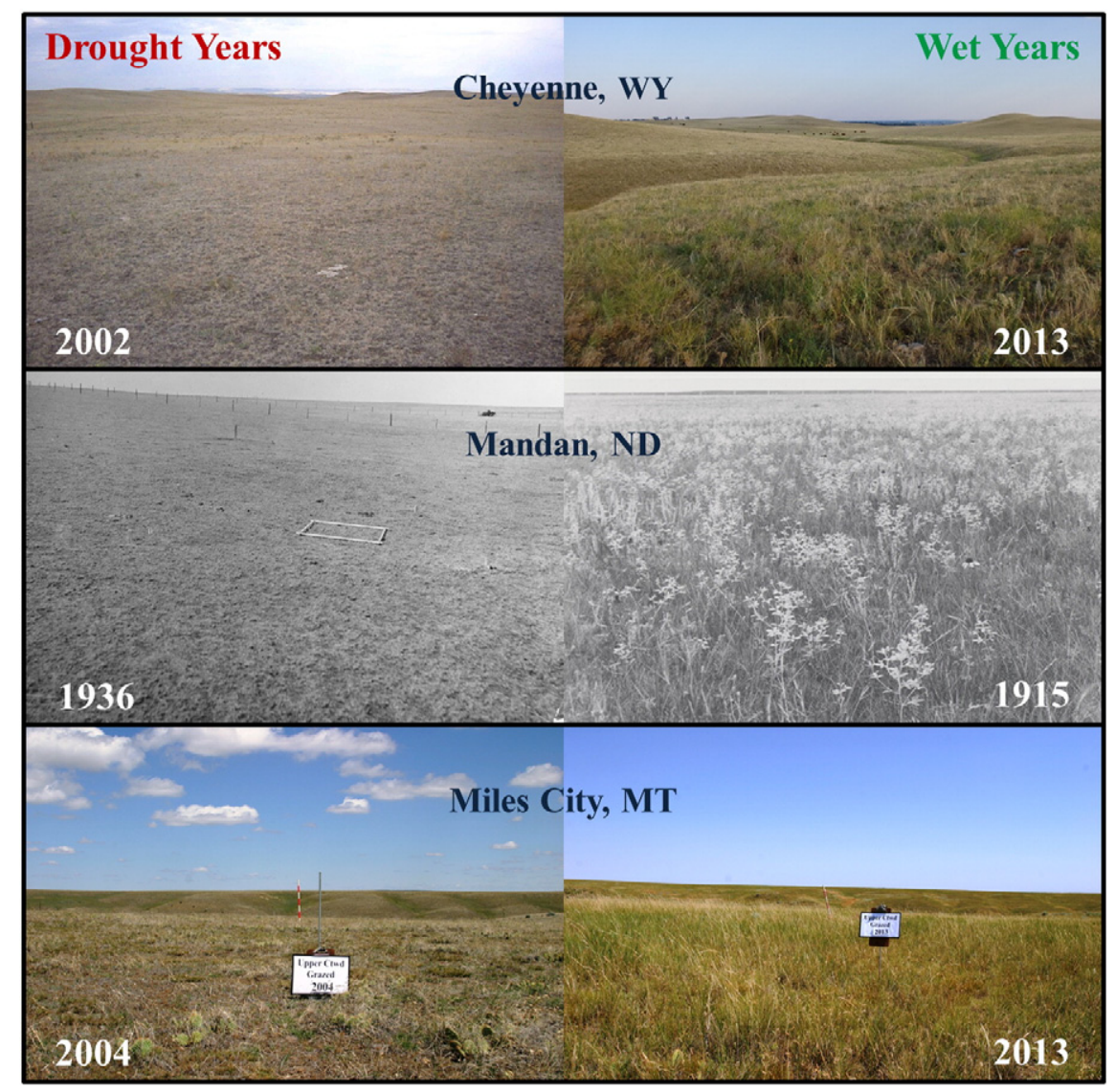

Figure 1. Photographic comparisons showing forage production in drought versus wet years for the research sites included in this article (see Box 1 for site details). Seasonal weather patterns can greatly affect forage and therefore cattle production in the Northern Great Plains.

planning ahead for, instead of reacting to, poor seasonal weather conditions.

\section{Project Overview}

Seasonal weather forecasts, such as the 1-month and 3-month outlooks available from the National Weather Service Climate Prediction Center ${ }^{\mathrm{i}}$ can be used in decision support tools to assist ranchers with decision making. ${ }^{5}$ To align with these free and easily accessible forecasts that are available up to 1 year in advance, we examined our datasets for effects of seasonal weather patterns using seasons for which prior data or forecasts could be attained easily by the public. Because both forage production ${ }^{1}$ and corresponding cattle production ${ }^{6}$ can be highly influenced by spring (April-June) precipitation in the Northern Great Plains, our research efforts focused, in part, on this seasonal weather variable. We also assessed the influence of summer (July-September), fall/ winter (October-March), and prior growing season (prior April-prior September) precipitation, along with spring and summer temperatures, on cattle production for all years in the historical datasets (Box 1). ${ }^{7-9}$

${ }^{\mathrm{i}}$ For more information on the National Weather Service Climate Prediction Center, visit http://www.cpc.ncep.noaa.gov/.

\section{How Does Seasonal Weather Influence Cattle Production in the Northern Great Plains?}

Cool, wet springs ${ }^{7-9}$ and longer, cooler growing seasons ${ }^{10}$ resulted in increased cattle production across the Northern

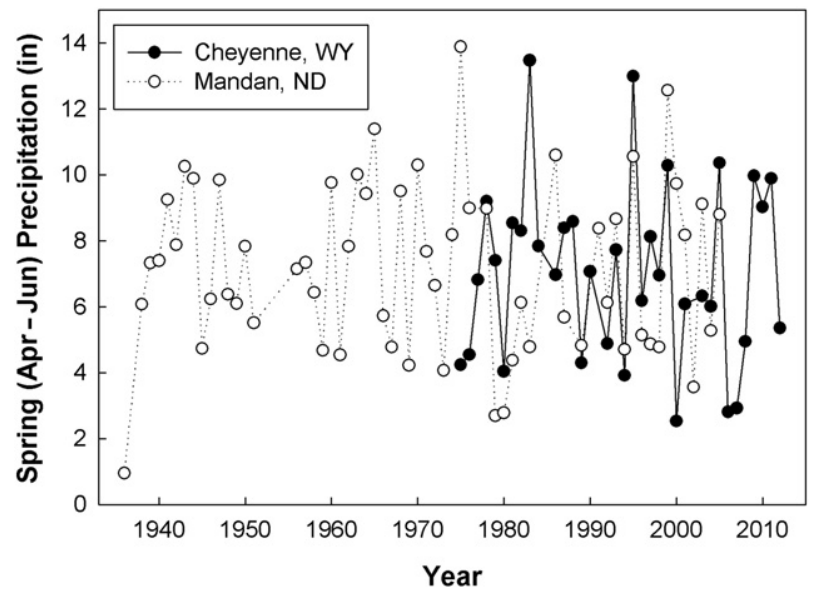

Figure 2. Spring (April-June) precipitation levels during study years for Cheyenne, Wyoming and Mandan, North Dakota research sites. Precipitation levels are highly variable from year to year, making it difficult for ranchers to make annual weather-related stocking rate decisions. This variability is expected to increase in coming decades, with more frequent extreme weather events such as severe droughts and downpours. 


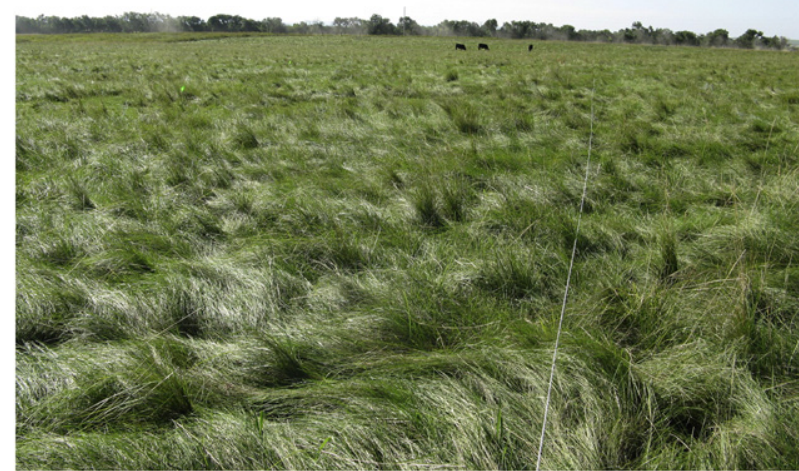

Figure 3. Kentucky bluegrass in experimental pasture in Mandan, North Dakota. Kentucky bluegrass invaded in the 1980s and now dominates the vegetation. Wet prior growing seasons and winters, along with cool, wet springs, became more important for cattle production on Kentucky bluegrass-invaded than native plant communities, as Kentucky bluegrass is most productive early in the growing season. Plant communities can greatly affect forage and therefore cattle response to seasonal weather patterns in the Northern Great Plains.

Great Plains. For ranchers, knowledge of such seasonal weather influences on cattle production is important for management decision making, but practical application of this knowledge remains somewhat problematic. For example, spring precipitation is highly erratic in the Northern Great Plains (Fig. 2), and the forecasts of spring seasonal precipitation from the National Weather Service simply provide the chances for above- or below-normal precipitation using a national map. This lack of ranch-scale specificity can make it difficult for ranchers to decide how to adjust stocking rates to either capitalize on anticipated wet springs or reduce negative effects for anticipated droughts. However, it is still possible to combine our results with these 3-month forecasts to assess risk associated with spring stocking decisions. For example, if the forecast calls for below normal spring (April-June) precipitation, there is a greater risk for low forage production (and perhaps overstocking), leading to problems later in the season. As such, spring stocking rate decisions can be critical because rainfall later in the grazing season (after the end of June) is not as effective for plant growth and cannot compensate for lost spring production. ${ }^{11}$ Seasonal forecasts, even those at national or regional scales, can provide valuable information for yearly decision making.

Beyond the common pattern of spring precipitation increasing cattle production, we found that response to seasonal weather patterns was influenced by plant community composition. For example, in the southern part of the Northern Great Plains, where warm-season grasses are a higher percentage of the plant community under heavier stocking rates, ${ }^{12}$ warm and wet summers increased cattle

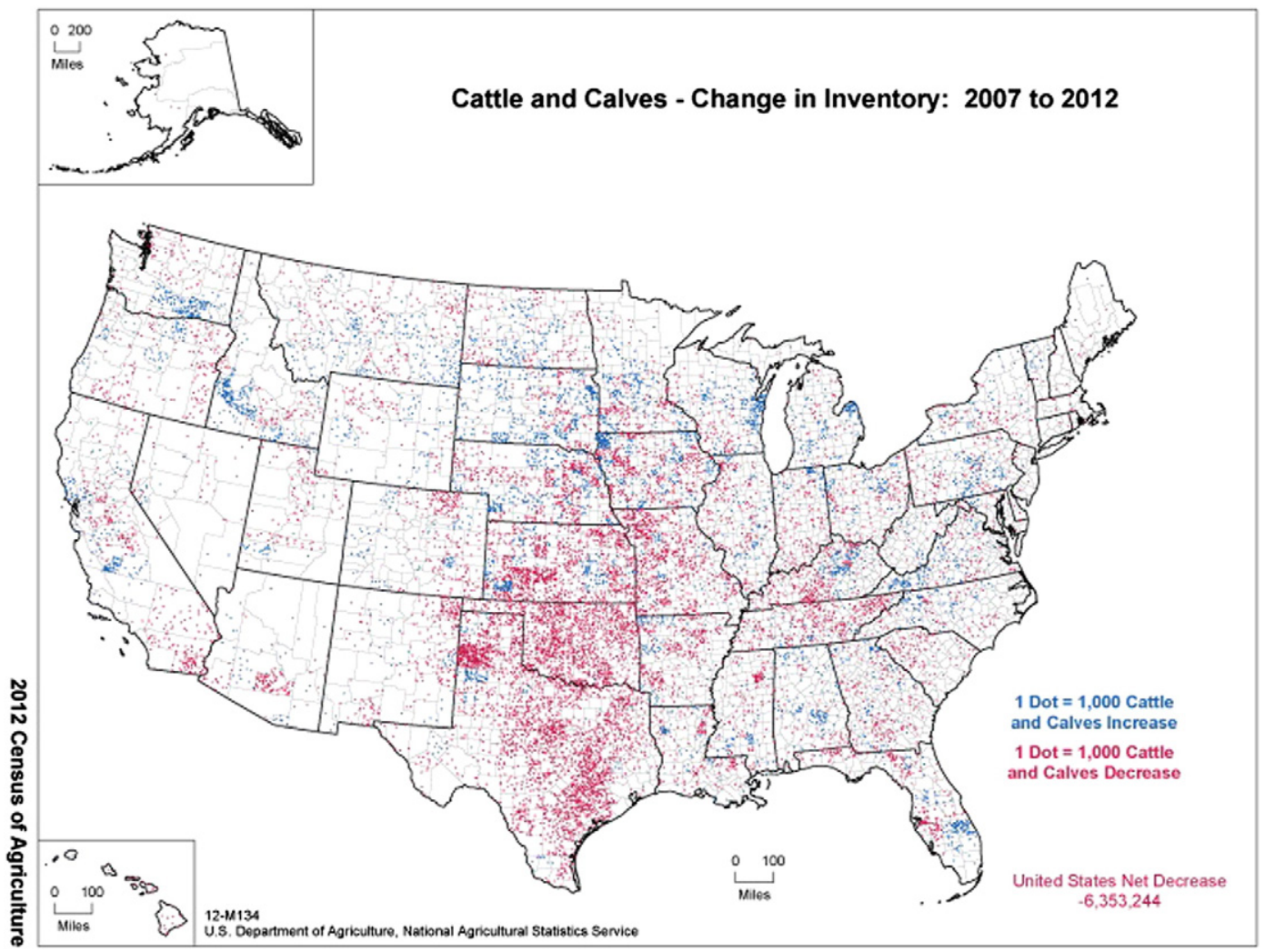

Figure 4. Distribution map (Map 12-M134 from USDA National Agricultural Statistics Service) showing change in cattle and calves inventory from 2007 to 2012. Each red dot represents 1,000 cattle and calves decrease; each blue dot represents 1,000 cattle and calves increase. Cattle numbers have been decreasing in the Southern Plains and increasing in the Northern Plains, although note that feedlot cattle (especially in the concentrated areas of dots) are likely playing a role in the observed map patterns. This northward movement of cattle can likely be expected to continue as climatic conditions become less favorable in the Southern Plains and potentially more favorable in the Northern Plains with climate change. 


\section{Box 1: ARS Research Site and Dataset Descriptions}

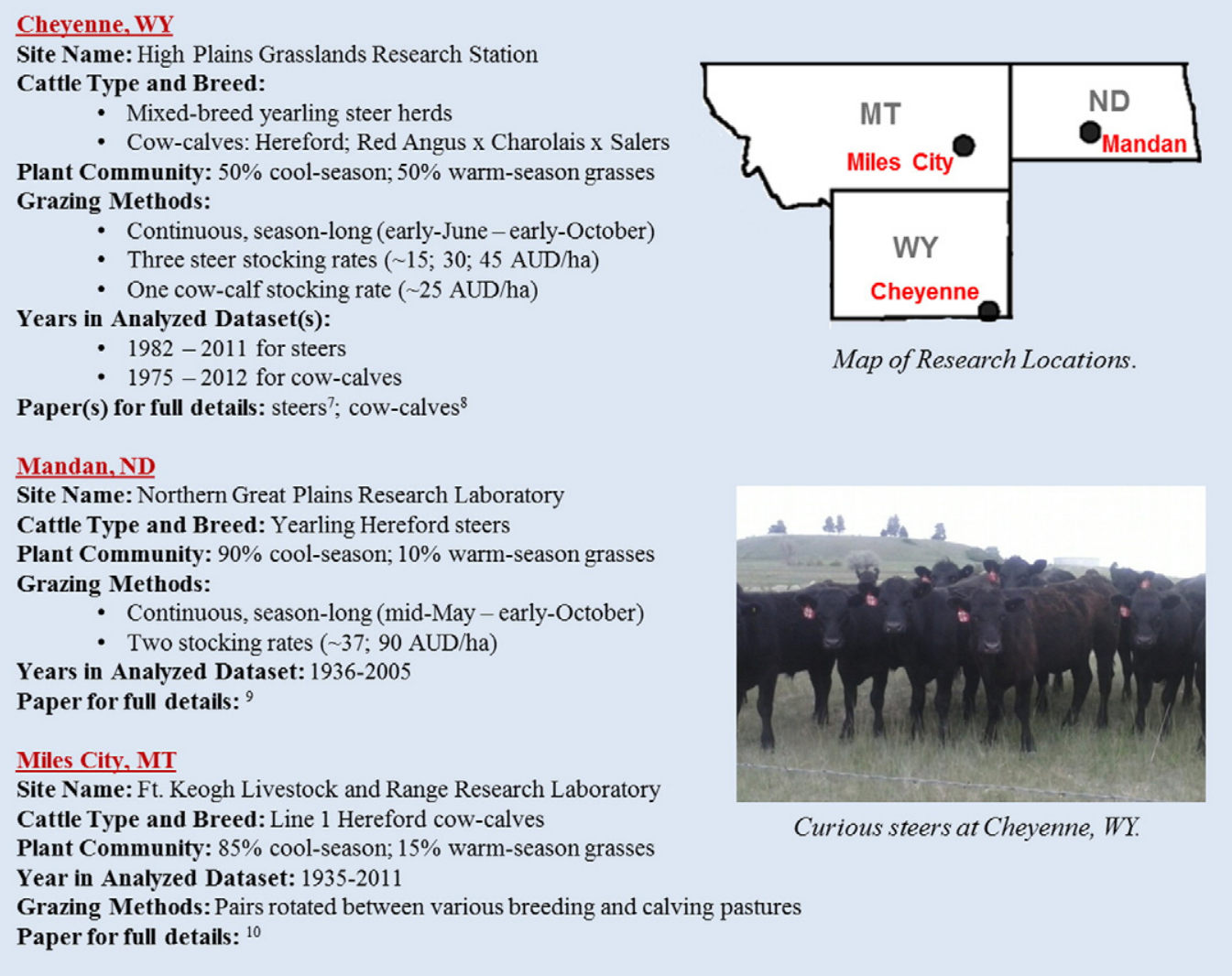

Box 1. ARS Research Site and Dataset Descriptions.

production. ${ }^{7}$ As another example, in North Dakota, where Kentucky bluegrass (Poa pratensis L.) invaded many rangelands beginning in the 1980s (Fig. 3), cool and wet springs, wet winters, and wet prior growing seasons were more influential on cattle production than for the native plant community. ${ }^{9}$ This is likely because Kentucky bluegrass is most productive and nutritious early in the growing season, making early-season soil moisture particularly important. Clearly, considering the forage type on a ranch, and even the distribution of forages around the ranch (e.g, proportions of cool- vs. warm-season grasses) can greatly help ranchers predict forage production response to forecasted seasonal weather patterns. This sort of site-specific, precision ranching will be advantageous for adapting to a changing climate.

Stocking rate was the final factor found in our studies to affect cattle production response to seasonal weather patterns. In both Mandan, North Dakota, and Cheyenne, Wyoming, where multiple stocking rates were used in experiments, heavier stocking rates increased cattle production sensitivity to weather patterns. That is, weather had a bigger influence on cattle production at higher stocking rates, and weather explained more of the yearly variation in cattle production at higher stocking rates. The general thought that higher stocking rates make ranchers more susceptible to poor weather patterns has been discussed in the literature before, ${ }^{13,14}$ and was clearly shown to be reality in our project. In cases of drought under heavy stocking rates, ranchers often are required to take actions such as emergency herd reductions. ${ }^{3,13}$ However, with some planning and foresight for mitigating the effects of seasonal weather patterns on cattle production, these negative effects can be minimized.

\section{Lessons Learned: Management Strategies for Ranchers}

Most ranching operations in the Northern Great Plains are cow-calf enterprises. ${ }^{2}$ However, in many cow-calf operations, logistical constraints can make it difficult to be flexible and adaptively manage grazing for the highly variable seasonal weather patterns and forage production. For example, genetic considerations of the herd can preclude quickly reducing herd numbers at the onset of dry/drought conditions. Ranchers can avoid such constraints and achieve higher economic returns and stability in the face of seasonal weather variability by reducing cow herd numbers to perhaps two-thirds or three-fourths of the typical carrying capacity of the ranch. Then, yearlings can be used to provide the flexibility in numbers of grazing animals across years for increasing or 
decreasing stocking rates to adjust to seasonal weather patterns and variable forage production. ${ }^{3,13,14}$ This strategy, when combined with accurate seasonal weather forecasts, could result in doubling economic returns for ranchers. ${ }^{13}$ Alternatively, seasonal contract grazing can also be used to increase overall ranch stocking rates in times of ample forage production. As a part of incorporating such strategies, there is a need for more reliable, site-specific seasonal weather forecasts to be developed. Future development of such forecasts may increase the relatively low numbers of ranchers that already incorporate seasonal weather forecasts in their decision making. ${ }^{3,4}$

\section{Future of Cattle Production in the Northern Great Plains}

Although many negative effects are predicted for most rangelands in the United States related to climate change, ${ }^{15,16}$ the Northern Plains region is predicted to potentially benefit. For example, spring and winter precipitation is expected to increase in the Northern Great Plains, which is anticipated to increase forage and therefore livestock production. ${ }^{15}$ However, anticipated warmer spring temperatures ${ }^{15,16}$ may offset some of this potential production increase. Regardless, the possible net increase in forage and livestock productivity may lead to an increase in cattle numbers in the Northern Great Plains in coming decades. The potential northward movement of cattle from the Southern Plains and Southwestern United States may already be underway (Fig. 4), and can probably be expected to continue as these regions are anticipated to experience less precipitation coupled with increased temperatures in coming decades. ${ }^{15}$

Other important issues related to climate change that may affect future cattle production in the Northern Great Plains include 1) increases in invasive species, 2) woody plant encroachment, 3) lengthened growing seasons, and 4) increases in extreme weather events (e.g., drought, downpours, heat waves, and cold spells). ${ }^{14-16}$ Potential respective adaptation strategies include using sheep and/or goats to control weeds and woody plants (although cattle themselves can be effective in some cases too ${ }^{17}$ ), beginning grazing seasons earlier and/or ending them later, not grazing some pastures ("grassbanking") to have emergency forage reserves in case of severe drought, and temporary geographical herd relocation. ${ }^{14}$

\section{New Resource for Enhancing Climate-Smart Decision Making by Ranchers}

The USDA has recently launched Regional Climate Hubs ${ }^{\text {ii }}$ to deliver science-based knowledge, practical information, management/conservation strategies, and decision tools such as the USDA-Natural Resources Conservation Service Drought Calculator to ranchers that may help them adapt

\footnotetext{
ii For more information on the USDA Regional Climate Hubs, visit http://climatehubs.oce.usda.gov.
}

to weather variability and changing climatic conditions. The USDA Northern Plains Regional Climate Hub ${ }^{\text {iii }}$ will provide technical support for responding to changing climate conditions such as drought, extreme weather events, and lengthening growing seasons by showcasing applied research and adaptation demonstrations through partnerships to reduce enterprise risk and enhance resilience of rangelands. For example, data from our multilocation research will be made available via the Climate Hub portal to agencies or commercial ventures for use in developing and disseminating decision tools for ranchers. Other outreach and education efforts and products will be provided to ranchers on science-based risk management through land grant universities, cooperative extension, and USDA service agencies.

\section{New Technological Resources for Enhancing Decision Making by Ranchers}

Remote sensing is a recently established technological advancement that can enhance weather-related decision making by estimating forage production from satellite imagery. However, prior remote sensing efforts to estimate forage production were at spatial scales too large for ranch- or pasture-level decision making. This is beginning to change, however, as recent developments have allowed for usable ranch-scale forage production estimates. ${ }^{18}$ For instance, research in Mandan, North Dakota, indicated potential for using satellite data to estimate forage quality and adjust stocking rates within the grazing season. ${ }^{19,20}$ Other current efforts are translating ranch-level satellite images and databases on weather, land use, and calibration models into a forage monitoring system in Argentina and Uruguay. ${ }^{21}$ In this system, forage production estimations are generated by the 15 th day of each month, with information sent by e-mail to interested ranchers. A similar type of initiative could provide ranchers in the Northern Great Plains with on-ranch, pasture-level estimates of forage production to enhance decision making related to rangeland cattle production (i.e., stocking rate adjustment and animal movements). As such, it is hoped that such a system will be available soon for the Northern Great Plains.

\section{Conclusions}

Ranching is a challenging and sometimes risky business, in part because highly variable seasonal weather patterns from year to year can cause rapid swings between boom and bust forage production. To effectively manage for such weather and forage variability, a better understanding of weather effects on cattle production is needed. Scientists with the USDA-ARS have begun to decipher these relationships using historical long-term datasets from the Northern Great Plains. Armed with the resulting knowledge that cool, wet springs, longer,

iii Additional information on the USDA Northern Plains Regional Climate Hub can be found at http://climatehubs.oce.usda.gov/northernplains-hub. 
cooler growing seasons, and other plant-community-specific weather patterns can increase forage and cattle production, ranchers can use multiple strategies to adaptively manage their enterprise. For instance, seasonal weather forecasts such as those described from the National Weather Service can potentially provide an indication of forage production well in advance of the grazing season, although more specific and more local forecasts are needed. Also, because stocking rate can increase cattle production sensitivity to weather patterns, cowcalf herds can be reduced to less than $100 \%$ of a given ranch's typical carrying capacity, with yearlings or seasonal contract grazing providing flexibility to increase forage utilization to normal (or even beyond) in times of ample forage production. New resources such as the USDA Regional Climate Hubs and remote sensing of forage production via satellite imagery will soon help to further facilitate effective decision making for ranchers in the Northern Great Plains. Using any number of these strategies will allow ranchers to plan for, instead of be forced to react to, poor seasonal weather conditions.

\section{References}

1. Derner, J.D., And R.H. Hart. 2007. Grazing-induced modifications to peak standing crop in northern mixed-grass prairie. Rangeland Ecology \& Management 60:270-276.

2. Kachergis, E., J. Derner, L. Roche, K. Tate, M. Lubell, R. Mealor, and J. Magagna. 2013. Characterizing Wyoming ranching operations: natural resource goals, management practices and information sources. Nature Resources 4:45-54.

3. Kachergis, E., J.D. Derner, B.B. Curtis, L.M. Roche, V.T. Eviner, M.K. LubELL, AND K.W. TATE. 2014. Increasing flexibility in rangeland management during drought. Ecosphere 5 [Article 77].

4. Marshall, N.A., I.J. Gordon, and A.J. Ash. 2011. The reluctance of resource-users to adopt seasonal climate forecasts to enhance resilience to climate variability on the rangelands. Climatic Change 107:511-529.

5. Derner, J.D., D.J. Augustine, J.C. Ascough, and L.R. Ahuja. 2012. Opportunities for increasing utility of models for rangeland management. Rangeland Ecology $\xi^{\circ}$ Management 65:623-631.

6. Derner, J.D., R.H. Hart, M.A. Smith, and J.W. Waggoner. 2008. Long-term cattle gain responses to stocking rate and grazing systems in northern mixed-grass prairie. Livestock Science 117:60-69.

7. Reeves, J.L., J.D. Derner, M.A. Sanderson, M.K. Petersen, L.T. Vermeire, J.R. Hendrickson, And S.L. Kronberg. 2013. Temperature and precipitation affect steer weight gains differentially by stocking rate in northern mixed-grass prairie. Rangeland Ecology E Management 66:438-444.

8. Reeves, J.L., J.D. Derner, M.A. Sanderson, M.K. Petersen, L.T. Vermeire, J.R. Hendrickson, and S.L. Kronberg. 2013. Seasonal temperature and precipitation effects on cow-calf production in northern mixed-grass prairie. Livestock Science 155:355-363.

9. Reeves, J.L., J.D. Derner, M.A. Sanderson, J.R. Hendrickson, S.L. Kronberg, M.K. Petersen, and L.T. Vermeire. 2014. Seasonal weather influences on yearling beef steer production in C3dominated Northern Great Plains rangeland. Agriculture, Ecosystems and Environment 183:110-117.

10. MacNeil, M.D., AND L.T. Vermeire. 2012. Effect of weather patterns on preweaning growth of beef calves in the Northern Great Plains. Agricultural Sciences 3:929-935.

11. Heitschmidt, R.K., And L.T. Vermeire. 2006. Can abundant summer precipitation counter losses in herbage production caused by spring drought? Rangeland Ecology E Management 59:392-399.
12. Manley, W.A., R.H. Hart, M.J. Samuel, M.A. Smith, J.W. Waggoner, And J.T. Manley. 1997. Vegetation, cattle, and economic responses to grazing strategies and pressures. Journal of Range Management 50:638-646.

13. Torell, L.A., S. Marugan, and O.A. Ramires. 2010. Economics of flexible versus conservative stocking strategies to manage climate variability risk. Rangeland Ecology \& Management 63:415-425.

14. Joyce, L.A., D.D. Briske, J.R. Brown, H.W. Polley, B.A. McCARL, AND D.W. Bailey. 2013. Climate change and North American rangelands: assessment of mitigation and adaptation strategies. Rangeland Ecology \& Management 66:512-528.

15. Polley, H.W., D.D. Briske, J.A. Morgan, K. Wolter, D.W. Bailey, And J.R. Brown. 2013. Climate change and North American rangelands: trends, projections, and implications. Rangeland Ecology Eं Management 66:493-511.

16. Walsh, J., D. Wuebbles, K. Hayhoe, J. Kossin, K. Kunkel, G. Stephens, P. Thorne, R. Vose, M. Wehner, J. Willis, D. Anderson, S. Doney, R. Feely, P. Hennon, V. Kharin, T. Knutson, F. Landerer, T. Lenton, J. Kennedy, and R. SomerviLle. 2014. Our changing climate. In: Melillo JM, Richmond TC, \& Yohe GW, editors. Climate change impacts in the United States: the third national climate assessment. . U.S. Global Change Research Program. p. 19-67, http://dx.doi.org/ 10.7930/J0KW5CXT.

17. De Brujjn, S.L., And E.W. Bork. 2006. Biological control of Canada thistle in temperate pastures using high density rotational cattle grazing. Biological Control 36:305-315.

18. Running, S.W., R.R. Nemani, F.A. Heinsch, M. Zhao, M. Reeves, and H. Hashimoto. 2004. A continuous satellitederived measure of global terrestrial primary production. Bioscience 54:547-560.

19. Beeri, O., R. Phillips, J. Hendrickson, A.B. Frank, and S. KRONBERG. 2007. Estimating forage quantity and quality using aerial hyperspecrtal imagery for northern mixed-grass prairie. Remote Sensing of the Environment 110:216-225.

20. Phillips, R., O. Beeri, E. Scholljegerdes, D. BjergaArd, AND J. HendRickson. 2009. Integration of geospatial and cattle nutrition information to estimate paddock grazing capacity in northern U.S. prairie. Agricultural Systems 100:72-79.

21. Grigera, G., M. Oesterheld, and F. Pacín. 2007. Monitoring forage production for farmers' decision making. Agricultural Systems 94:637-648.

Authors are Research Ecologist, (Reeves, Justin.Reeves@ars.usda.gov), and Research Leader (Derner), US Dept of AgricultureAgricultural Research Service-Rangeland Resources Research Unit, Cheyenne, WY 82009, USA; Research Leader (Sanderson), Research Animal Scientist (Kronberg), and Research Rangeland Management Specialist (Hendrickson), US Dept of Agriculture-Agricultural Research Service-Northern Great Plains Research Laboratory, Mandan, ND 58554, USA; Research Ecologist (Vermeire), and Research Leader (Petersen), US Dept of Agriculture-Agricultural Research Service-Ft Keogh Livestock and Range Research Laboratory, Miles City, MT 59301, USA; Postdoctoral Research Associate ${ }^{1}$ and Assistant Scientist ${ }^{2}$ (Irisarri), ${ }^{1}$ Department of Agricultural and Applied Economics, University of Wyoming, Laramie, WY 82071, USA and ${ }^{2}$ Catedra de ForrajiculturaIFEVA-Facultad de Agronomia Universidad deBuenos AiresCONICET, CABA 1417, Argentina. 